\title{
Percent per Minute
}

National Cancer Institute

\section{Source}

National Cancer Institute. Percent per Minute. NCI Thesaurus. Code C114240.

A unit of frequency expressed as the percentage of entities or events per minute. 